\title{
Computerized decision making in myocardial perfusion SPECT: The new era in nuclear cardiology?
}

\author{
Elin Trägårdh, MD, PhD, ${ }^{\text {a }}$ Marcus Carlsson, MD, PhD, ${ }^{\mathrm{b}}$ and Lars Edenbrandt, \\ MD, PhD ${ }^{a}$ \\ ${ }^{a}$ Clinical Physiology and Nuclear Medicine, Lund University, Skåne University Hospital, Malmö, \\ Sweden \\ ${ }^{\mathrm{b}}$ Clinical Physiology and Nuclear Medicine, Lund University, Skåne University Hospital, Lund, \\ Sweden
}

Received Nov 21, 2014; accepted Nov 21, 2014

doi: 10.1007/s12350-014-0041-z

See related article, pp. 877-884

In this issue of the journal, Arsanjani et al. ${ }^{1}$ investigate if early revascularization can be predicted by automatic integration of clinical data and image data from myocardial perfusion SPECT (MPS). It has previously been shown that a normal or mildly abnormal MPS is associated with a low frequency of referral for coronary revascularization $^{2}$ and that a normal MPS is associated with a very low annual risk of cardiac death and acute myocardial infarction. ${ }^{3-5}$

\section{COMPUTER AID IN MPS}

One of the problems with interpretation of MPS, as well as other imaging modalities, is that it is dependent on the knowledge of the interpreting physician, and is subject to intra-observer variability. ${ }^{6}$ To, at least in part, overcome this inconvenience, software packages for automated quantification and also interpretation of MPS have been developed. Measurements of ejection fraction and cardiac volumes have been available since gated MPS was introduced. Semi-quantification of the perfusion data has also been around for some time, e.g., summed stress score, summed rest score, and summed difference score. It is, however, known that these automated measurements

\footnotetext{
Reprint requests: E. Trógârdh, $\mathrm{MD}, \mathrm{PhD}$, Clinical Physiology and Nuclear Medicine, Skâne University Hospital, Inga Marie Nilssons Gata 49, 205 02, Malmó, Sweden; elin.tragardh@med.lu.se J Nucl Cardiol 2015;22:885-7. $1071-3581 / \$ 34.00$

Copyright (C) 2014 American Society of Nuclear Cardiology.
}

differ between different software packages. ${ }^{7-9}$ More sophisticated methods for standardizing MPS include computed-aided diagnosis (CAD). CAD systems are common in certain areas of medicine, e.g., electrocardiography, ${ }^{10}$ but are increasingly used also in nuclear medicine. It could provide second opinion for inexperienced physicians but could also serve to make interpretations more objective and less user dependent. A previous study ${ }^{11}$ has found improvements in the average physician performance with regard to sensitivity, specificity, and accuracy when using neural networks for MPS interpretation. It was also found that although there were significant differences between physicians' interpretations before the computer aid, these differences were not present after CAD. Another study ${ }^{6}$ found that physicians improve their consistency with a CAD system, even among highly experienced physicians. Today, most software tools for evaluating MPS studies use some sort of CAD system, where the more advanced are based on machine learning techniques such as artificial neural networks. With the study by Arsanjani et al. ${ }^{1}$ in this issue of the journal, prediction of treatment has now been investigated with the help of another machine learning technique.

\section{GUIDELINES ON REVASCULARIZATION}

There is a distinction between what treatment the patient is likely to receive and what treatment the patient should be given. The recommendations for when to refer patients with stable angina pectoris to invasive coronary angiography and revascularization after non-invasive imaging, differ slightly between different European and US guidelines, especially regarding the amount of ischemia and how it is calculated. In the European guidelines 
on management of stable coronary heart disease, patients with high event risk (mortality $\geq 3 \%$ /year) should undergo invasive coronary angiography and revascularization " "when appropriate.", 12 High risk after ischemia imaging is defined as "area of ischemia $>10 \%$,' which for MPS equals " $\geq 2$ of 17 segments." The guidelines state that there are limited quantitative data for cardiovascular magnetic resonance imaging-probably $\geq 2 / 16$ segments with perfusion defects or $\geq 3$ dobutamine-induced dysfunctional segments, and $\geq 3$ segments by stress echo. In the European guidelines on myocardial revascularization, there is a class 1B indication for revascularization of patients with stable or silent angina pectoris with a "large area of ischemia ( $>10 \%$ left ventricle)."13 The recommendation is based on studies performed by Shaw et al. ${ }^{14}$ and Hachamovitch et al. ${ }^{15,16}$ There are several problems with the recommendation in the guidelines. First, " $10 \%$ ", In the original studies, it was found that equipoise between the strategies optimal medical therapy and revascularization was present at $\sim 10-15 \%$ myocardium ischemic. Second, the guidelines state "area,' but the studies by Hachamovitch et al. used scoring system for assessing the ischemic amount, thus integrating both extent (area), and severity of perfusion defects. Third, the cut-off of 10-15\% was found only in patients without previous myocardial infarction on MPS, which is not mentioned in the guidelines. Fourth, the guidelines do not clearly state that the studies were performed using MPS, and that it is not yet known how this translates to other modalities, such as cardiovascular magnetic resonance, computed tomography, and invasive angiography.

In the US guidelines, ${ }^{17}$ it is stated that "percutaneous coronary intervention reduces the incidence of angina, has not been demonstrated to improve survival in stable patients, may increase the short-term risk of myocardial infarction, and does not lower the long-term risk of myocardial infarction.' Regarding left main disease, it is stated that "coronary artery bypass grafting to improve survival is reasonable in patients with significant $(\geq 70 \%$ diameter) stenoses in 2 major coronary arteries with severe or extensive myocardial ischemia (e.g., high-risk criteria on stress testing, abnormal intracoronary hemodynamic evaluation, or $>20 \%$ perfusion defect by myocardial perfusion stress imaging.' According to the US guidelines, reversible perfusion defects encompassing $>10 \%$ or the myocardium (determined either with summed scores or quantitatively) are considered moderately abnormal, and reversible perfusion defects $>15 \%$ are considered severely abnormal.

\section{FUTURE DIRECTIONS}

The article by Arsanjani et al. ${ }^{1}$ deals with if it is possible to, in an automatic way, predict if a patient will receive revascularization shortly after the MPS. The clinical benefit of computer advice based on automatic analysis could be reduced to the need for invasive testing by reducing the number of angiographic procedures not followed by revascularization. Especially less experienced readers would benefit from this type of advice. The study indicates the potential of such a computer advice.

Future steps in the development of such computer advice systems will include all patients admitted to myocardial perfusion imaging. A system that could separate patients that would benefit from revascularization from those who would not in consecutive series of patients would be of great value for the less experienced reader. The present study was based on only $5 \%$ of all patients who underwent MPS. The approach to include only a fraction of patients referred for MPS in the validation of quantitative methods has been used before. Wolak et al. ${ }^{8}$ and Guner et al. ${ }^{7}$ included $12-13 \%$ of the patients referred to MPS based on a selection of patients with a low likelihood of coronary artery disease and patients with a coronary angiogram after the MPS. The need for advice for the less experienced reader is greatest for borderline cases not included in these studies.

\section{Conflict of interest}

LE is a shareholder and is employed by EXINI Diagnostics AB, Lund, Sweden

\section{References}

1. Arsanjani R, Dey D, Khachatryan T, Shalev A, Hayes SW, Fish $M$, et al. Prediction of revascularization after myocardial perfusion SPECT by machine learning in a large population. J Nucl Cardiol 2014. doi:10.1007/s12350-014-0027-x.

2. Hachamovitch R, Nutter B, Hlatky MA, Shaw LJ, Ridner ML, Dorbala $\mathrm{S}$, et al. Patient management after noninvasive cardiac imaging results from SPARC (Study of myocardial perfusion and coronary anatomy imaging roles in coronary artery disease). J Am Coll Cardiol 2012;59:462-74.

3. Metz LD, Beattie M, Hom R, Redberg RF, Grady D, Fleischmann $\mathrm{KE}$. The prognostic value of normal exercise myocardial perfusion imaging and exercise echocardiography: A meta-analysis. J Am Coll Cardiol 2007;49:227-37.

4. Shaw LJ, Iskandrian AE. Prognostic value of gated myocardial perfusion SPECT. J Nucl Cardiol 2004;11:171-85.

5. Navare SM, Mather JF, Shaw LJ, Fowler MS, Heller GV. Comparison of risk stratification with pharmacologic and exercise stress myocardial perfusion imaging: A meta-analysis. J Nucl Cardiol 2004;11:551-61.

6. Lindahl D, Lanke J, Lundin A, Palmer J, Edenbrandt L. Improved classifications of myocardial bull's-eye scintigrams with computer-based decision support system. J Nucl Med 1999;40:96-101.

7. Guner LA, Karabacak NI, Cakir T, Akdemir OU, Kocaman SA, Cengel A, et al. Comparison of diagnostic performances of three different software packages in detecting coronary artery disease. Eur J Nucl Med Mol Imaging 2010;37:2070-8. 
8. Wolak A, Slomka PJ, Fish MB, Lorenzo S, Acampa W, Berman DS, et al. Quantitative myocardial-perfusion SPECT: Comparison of three state-of-the-art software packages. J Nucl Cardiol 2008;15:27-34.

9. Svensson A, Akesson L, Edenbrandt L. Quantification of myocardial perfusion defects using three different software packages. Eur J Nucl Med Mol Imaging 2004;31:229-32.

10. Heden B, Ohlin H, Rittner R, Edenbrandt L. Acute myocardial infarction detected in the 12-lead ECG by artificial neural networks. Circulation 1997;96:1798-802.

11. Guner LA, Karabacak NI, Akdemir OU, Karagoz PS, Kocaman SA, Cengel A, et al. An open-source framework of neural networks for diagnosis of coronary artery disease from myocardial perfusion SPECT. J Nucl Cardiol 2010;17:405-13.

12. Montalescot G, Sechtem U, Achenbach S, Andreotti F, Arden C, Budaj A, et al. 2013 ESC guidelines on the management of stable coronary artery disease: The Task Force on the management of stable coronary artery disease of the European Society of Cardiology. Eur Heart J 2013;34:2949-3003.

13. Windecker S, Kolh P, Alfonso F, Collet JP, Cremer J, Falk V, et al. 2014 ESC/EACTS Guidelines on myocardial revascularization: The Task Force on Myocardial Revascularization of the European Society of Cardiology (ESC) and the European Association for Cardio-Thoracic Surgery (EACTS)Developed with the special contribution of the European Association of Percutaneous Cardiovascular Interventions (EAPCI). Eur Heart J 2014;35:2541619.
14. Shaw LJ, Berman DS, Maron DJ, Mancini GB, Hayes SW, Hartigan PM, et al. Optimal medical therapy with or without percutaneous coronary intervention to reduce ischemic burden: Results from the Clinical Outcomes Utilizing Revascularization and Aggressive Drug Evaluation (COURAGE) trial nuclear substudy. Circulation 2008;117:1283-91.

15. Hachamovitch R, Hayes SW, Friedman JD, Cohen I, Berman DS. Comparison of the short-term survival benefit associated with revascularization compared with medical therapy in patients with no prior coronary artery disease undergoing stress myocardial perfusion single photon emission computed tomography. Circulation 2003;107:2900-7.

16. Hachamovitch R, Rozanski A, Shaw LJ, Stone GW, Thomson LE, Friedman JD, et al. Impact of ischaemia and scar on the therapeutic benefit derived from myocardial revascularization vs. medical therapy among patients undergoing stress-rest myocardial perfusion scintigraphy. Eur Heart J 2011;32:1012-24.

17. Fihn SD, Gardin JM, Abrams J, Berra K, Blankenship JC, Dallas AP, et al. 2012 ACCF/AHA/ACP/AATS/PCNA/SCAI/STS guideline for the diagnosis and management of patients with stable ischemic heart disease: A report of the American College of Cardiology Foundation/American Heart Association task force on practice guidelines, and the American College of Physicians, American Association for Thoracic Surgery, Preventive Cardiovascular Nurses Association, Society for Cardiovascular Angiography and Interventions, and Society of Thoracic Surgeons. Circulation 2012;126:e354-471. 